\title{
THE EFFECTIVENESS OF TVS (TRANSVAGINAL ULTRASOUND) IN DIAGNOSIS OF ECTOPIC PREGNANCY
}

\author{
Lubna Rashid Gilkar', Shaheera Ajaz², Waseem Jan Shah ${ }^{3}$
}

${ }_{1}^{1}$ Senior Resident, Department of Obstetrics and Gynaecology, SKIMS, Srinagar, Jammu and Kashmir, India.

${ }^{2}$ Senior Resident, Department of Obstetrics and Gynaecology, SKIMS, Srinagar, Jammu and Kashmir, India.

${ }_{3}^{3}$ MCH Resident, Department of Paediatric Surgery, Moulana Azad Medical College, New Delhi, India.

\begin{tabular}{l}
\hline ABSTRACT \\
BACKGROUND \\
Ectopic pregnancy is a serious disaster in the reproductive life of a woman and is a major gynaecological emergency associated \\
with increased mortality, decreased reproductive potential and is recurrent. Timely diagnosis of the ectopic pregnancy is lifesaving \\
and also decreases number of operative procedures including diagnostic laparoscopy. We wanted to assess the effectiveness of TVS \\
in diagnosis of ectopic pregnancy.
\end{tabular}

\section{METHODS}

110 patients who were operated for ectopic tubal pregnancies were evaluated retrospectively by reviewing their medical records of TVS done preoperatively, for diagnosing ectopic pregnancy from April 2012 to March 2014. Ectopic pregnancy visualized at laparoscopy/laparotomy was used as the gold standard. Data recorded included intraoperative findings of 110 cases of operated ectopic pregnancies and TVS findings of all 110 cases, which were done preoperatively.

\section{RESULTS}

TVS done preoperatively in all these 110 cases showed that $60 \%$ had inhomogeneous mass adjacent to ovary, $20.8 \%$ had a mass with hyper echoic ring around gestational sac, $8 \%$ had G. Sac with foetal pole without cardiac activity, 4\% had G. Sac with foetal pole with cardiac activity and $7.2 \%$ had inconclusive scan. The sensitivity and positive predictive value of TVS to detect ectopic pregnancy in our study was $90.7 \%$ and $93.3 \%$ respectively.

\section{CONCLUSIONS}

This study demonstrates the effectiveness of transvaginal ultrasound to positively identify an ectopic pregnancy. Therefore, TVS is effective in diagnosis of ectopic pregnancy.

HOW TO CITE THIS ARTICLE: Gilkar LR, Ajaz S, Shah WJ. The effectiveness of TVS (Transvaginal Ultrasound) in diagnosis of ectopic pregnancy. J. Evolution Med. Dent. Sci. 2019;8(22):1777-1779, DOI: 10.14260/jemds/2019/390

\section{BACKGROUND}

Ectopic pregnancy is a serious disaster in the reproductive life of a woman and is a major gynaecological emergency associated with increased mortality, decreased reproductive potential and is recurrent. The diagnosis of ectopic pregnancy is difficult. Sometimes findings are non-specific and can mimic variety of clinical conditions. Less than half of the patients with ectopic pregnancy can be accurately diagnosed based on clinical features alone. 1

Diagnostic accuracy has been improved by advances in medical biochemistry and medical biophysics which in turn has reduced morbidity and mortality. ${ }^{2}$

In the confidential enquiries into maternal deaths in United Kingdom (1991-1993), it was common cause of maternal mortality. ${ }^{3}$ while in US in 1992 it contributed 9\% of all pregnancy related deaths. ${ }^{4}$

'Financial or Other Competing Interest': None.

Submission 09-12-2018, Peer Review 22-03-2019,

Acceptance 28-03-2019, Published 03-06-2019.

Corresponding Author:

Shaheera Ajaz,

Senior Resident,

Department of Obstetrics and Gynaecology,

SKIMS, Srinagar,

Jammu and Kashmir,

India.

E-mail: shaheeraajaz900@gmail.com

DOI: $10.14260 /$ jemds $/ 2019 / 390$
Those with ruptured ectopic with haemodynamic instability should undergo urgent surgery. However, in clinically stable women, transvaginal ultrasonography (TVS) is lifesaving and also reduces operative procedures like diagnostic laparoscopy. Besides TVS allows for consideration of conservative management options such as methotrexate or even an expectant approach by diagnosing ectopic early.5,6,7

\section{Aim of The Study}

We wanted to assess the effectiveness of TVS in the diagnosis of ectopic pregnancy.

\section{METHODS}

This study was a retrospective review of 110 patients with a surgically documented diagnosis of ectopic pregnancy, conducted at Lalla Ded Hospital of Government Medical College, Srinagar between April 2012 to March 2013.

These 110 patients who were operated for ectopic tubal pregnancies were evaluated retrospectively by reviewing their medical records of TVS, done preoperatively for diagnosing ectopic pregnancy. Ectopic was diagnosed by TVS as on one of the following appearances-

1. An inhomogeneous mass adjacent to ovary.

2. A mass with hyper-echoic ring around gestational sac.

3. A gestational sac with a foetal pole with cardiac activity.

4. A gestational sac with a foetal pole without cardiac activity. 
Ectopic pregnancy visualized at laparoscopy / laparotomy was used as the gold standard. Data recorded included Intraoperative findings of 110 cases of operated ectopic pregnancies and TVS findings of all 110 cases, which were done preoperatively.

\section{Statistical Analysis}

Descriptive statistics was used to analyse the data. The data was expressed as mean \pm SD. Performance of TVS was expressed in terms of sensitivity, positive predictive value.

\section{RESULTS}

This study was carried in government LD Hospital Srinagar from April 2012 - March 2013. In present study 110 patients underwent surgery (Laparotomy or laparoscopy) for presumed ectopic pregnancy. The mean age of the patients was $30.62 \pm 2.42$ years. The baseline characteristics are shown in Table 1. Out of them, 105 were true ectopics and were managed accordingly. However out of rest 5 cases, 2 cases had ruptured ovarian haemorrhagic cysts, 2 cases had negative laparotomy and 1 had right chocolate cyst.

TVS done preoperatively in all these 110 cases showed $60 \%$ had inhomogeneous mass adjacent to ovary, $20.8 \%$ had a mass with hyper echoic ring around gestational sac, $8 \%$ had G. Sac with foetal pole without cardiac activity, $4 \%$ had G. Sac with foetal pole with cardiac activity and $7.2 \%$ had inconclusive scan as shown in table 2 .

\begin{tabular}{|c|c|}
\hline Baseline Characteristics & \% Age of Cases \\
\hline Age > 30 Years & 56.4 \\
\hline Smoking & 4.5 \\
\hline Parity 1 & 65.6 \\
\hline Abortions & 22.7 \\
\hline PID & 20 \\
\hline Tuberculosis & 10 \\
\hline \multicolumn{2}{|c|}{ Table 1. Baseline Characteristics } \\
\hline
\end{tabular}

\begin{tabular}{|c|c|}
\hline Inhomogeneous mass adjacent to ovary & $60 \%$ \\
\hline A mass with hyper-echoic ring around G. Sac. & $20.8 \%$ \\
\hline G. Sac with foetal pole without cardiac activity & $8 \%$ \\
\hline With cardiac activity & $4 \%$ \\
\hline Inconclusive & $7.2 \%$ \\
\hline \multicolumn{2}{|c|}{ Table 2. TVS Findings in Ectopic Pregnancy } \\
\hline
\end{tabular}

The sensitivity and positive predictive value of TVS to detect ectopic pregnancy in our study was $90.7 \%$ and $93.3 \%$ respectively

\section{DISCUSSION}

Transvaginal sonography has changed management options of ectopic pregnancy by timely diagnosis. Conservative options, such as methotrexate, can be offered to haemodynamically stable patients and those with small ectopic. ${ }^{8,9}$ It has also reduced the associated mortality, morbidity and subsequent emergency laparotomy. ${ }^{10}$ TVS enables for laparoscopy to be reserved for its treatment only rather than diagnosis. ${ }^{11}$

Ectopic pregnancy is diagnosed by the positive visualization of an adnexal mass using 2D TVS.10. Ectopic can be diagnosed in 87 to $93 \%$ using TVS 12,13

In our study sensitivity and positive predictive value of TVS were $90.7 \%$ and $93.3 \%$ respectively which is analogous to the observation of Condous G, Khalid A et al (2005). ${ }^{14}$ In their study sensitivity and positive predictive value was $90.2 \%$ and $95.2 \%$ respectively. Cacciatore etal (1990) ${ }^{12}$ demonstrated sensitivity of $93 \%$ and positive predictive value of $98 \%$ of TVS alone while as it increased to $97 \%$ when combined with serum beta hCG, with equivalent specificity and positive predictive value. Hopp H, Schaar P, Entezami M et al (1995) ${ }^{15}$ gave sensitivity of TVS in diagnosing ectopic pregnancy as $96 \%$ and positive predictive value as $89 \%$. Our observations matched well with the observations made by these authors.

\section{CONCLUSIONS}

Our study clearly demonstrates the ability of transvaginal ultrasound when used as a single test, to positively identify an ectopic pregnancy. TVS is an effective diagnostic tool in the diagnosis of ectopic pregnancy.

\section{REFERENCES}

[1] Tuomivaara L, Kauppila A, Puolakka J. Ectopic pregnancy: an analysis of the aetiology, diagnosis and treatment in 522 cases. Arch Gynaecol 1986;237(3):135-47.

[2] Kadar N, DeVore G, Romero R. Discriminatory HCG zone: its use in sonographic evaluation of ectopic pregnancy. Obstet Gynecol 1981;58(2):156-61.

[3] Lewis G. The Confidential Enquiry into Maternal and Child health (CEMACH). Saving Mothers' Lives: Reviewing Maternal deaths to make Motherhood safer - 2003-2005. The Seventh Report on Confidential Enquiries into Maternal deaths in the United Kingdom. London: CEMACH, 2007.

[4] Maymon R, Halperin R, Mendlovic S, et al. Ectopic pregnancies in a Caesarian scar: review of the medical approach to an iatrogenic complication. Human Reprod Update 2004;10(6):515-23.

[5] Atri M, Valenti DA, Bret PM, et al. Effect of Transvaginal sonography on the use of invasive procedures for evaluating patient's within a clinical diagnosis of ectopic pregnancy. J Clin Ultrasound 2003;31(1):1-8.

[6] Hajenius PJ, Engelsbel S, Moi BW, et al. Randomised trial of systemic methotrexate versus laproscopic salpingostomy in tubal pregnancy. Lancet 1997;350(9080):774-9.

[7] Korhonen J, Stenman UH, Ylostalo P. Serum human chorionic gonadotropin dynamics during spontaneous resolution of ectopic pregnancy. Fertil Steril 1994;61(4):632-6.

[8] Orife J, Magowan B. Clinical Obstetrics and Gynaecology. London, United Kingdom: Saunders 2004: p. 169-71.

[9] Sowter MC, Farquhar CM, Petrie KJ, et al. A randomized trial comparing single dose systemic methotrexate and laproscopic surgery for the treatment of unruptured tubal pregnancy. $\mathrm{Br} \mathrm{J}$ Obstet \& Gynecol 2001;108(2):192-203.

[10] Condous G. Ectopic pregnancy - risk factors and diagnosis. Aust Fam Physician 2006;35(11):854-7.

[11] Sawyer E, Jukovic D. Ultrasonography in the diagnosis and management of abnormal early pregnancy. Clin Obstet Gynecol 2007;50(1):31-54. 


\section{Jemds.com}

[12] Cacciatore B, Stenman OH, Ylostalo P. Diagnosis of ectopic pregnancy by vaginal ultrasonography in combination with a discriminatory serum HCG level of 1000 IU/L (IRP). $\mathrm{Br} \quad \mathrm{J}$ Obstet Gynaecol 1990;97(10):904-8.

[13] Shalev E, Yarom I, Bustan M, et al. Transvaginal Sonography as the ultimate diagnostic tool for the management of ectopic pregnancy: experience of 840 cases. Fertil Steril 1998;69(1):62-5.

\section{Original Research Article}

[14] Condous G, Okaro E, Khalid A, et al. The accuracy of transvaginal ultrasonography for the diagnosis of ectopic pregnancy prior to surgery. Hum Reprod 2005;20(5):1404-9.

[15] Hopp HB, Schaar P, Entezami M, et al. Geburtshilfe Frauenheikunde. $\mathrm{Br} \quad \mathrm{J}$ Obstet Gynaecol 1995;55(12):666-70. 